medical trainee satisfaction. With junior doctor morale at an all-time low, we set out to improve the quality of communication in our region, as well as to enhance trainee education and collaboration.

Methods We surveyed trainees on their use and opinions of current regional communication channels - a School of Paediatrics website, emails, and a trainee-led Facebook group. Survey results were used to guide the development of a new networking platform, The Hub.

Results The existing School of Paediatrics website was infrequently used; 94\% of trainees accessed it a few times a year or less, mostly to obtain forms and policies. While the trainee-led Facebook group was more frequently viewed, active participation was uncommon. Over $80 \%$ of trainees agreed that a region-wide networking platform would be valuable. The most requested features were sub-specialty interest groups, regional information including training opportunities, and a calendar of work and social events.

Several online platforms were assessed for hosting The Hub; the open-source Trello was chosen for its free availability, ease-of-use, and clearly defined privacy and information policies. We created a central School of Paediatrics Hub, as well as boards for different training levels and committees, and several sub-specialty interest groups.

While trainees are the core Hub members, representatives from the School of Paediatrics and other colleagues also contribute. Content is user-generated and published live, allowing for dynamic collaboration, discussion and resource sharing. In the first four months, over $90 \%$ of trainees in the region joined; members created 222 new 'cards', and shared 445 comments and 221 attachments. The Hub is updated and extended based on feedback and demand.

Conclusion The Hub consolidates several disparate communication channels, and should enable more effective peer-to-peer networking and collaboration. The flexible platform continues to evolve based on members' needs, and could be expanded to other regions and specialities. We aim to conduct further surveys of Hub members to assess the impact on communication and to guide future improvements.

\section{G103 THAT'S WHAT CHUMS ARE FOR - BENEFITS OF A MEDICAL STUDENT PAEDIATRIC VOLUNTEERING SERVICE}

${ }^{1} V$ Stokes, ${ }^{1} \mathrm{O}$ Horton, ${ }^{1} \mathrm{E}$ Nolan, ${ }^{1} \mathrm{C}$ Ashton, ${ }^{1} \mathrm{C}$ Edwards, ${ }^{1} \mathrm{~S}$ Parsons, ${ }^{2} \mathrm{~N}$ Davis, ${ }^{3} \mathrm{E}$ Jameson. ${ }^{1}$ Undergraduate Medicine, University of Manchester, Manchester, UK; ${ }^{2}$ Royal Manchester Children's Hospital, Manchester Foundation Trust, Manchester, UK; ${ }^{3}$ St Mary's Hospital, Manchester Foundation Trust, Manchester, UK

\subsection{6/archdischild-2018-rcpch.100}

Aims Medical students from the University of Manchester interested in a paediatric career started a society called CHUMS (Children's Hospital University of Manchester Students). The primary aim was to improve patient and parent/ carer experience by providing play sessions at Royal Manchester Children's Hospital (RMCH). A secondary aim was to assess the impact sessions had on patient mood and pain scores.

Methods CHUMS is run by a student committee and is a recognised University society. It is overseen by two $\mathrm{RMCH}$ paediatric consultants and is supported by the Trust's 'Transform Together' team. Student volunteers are recruited through an application process and undergo play therapy training.
Volunteers attend 4 of the 7 wards and PED. Questionnaires are collected from the children to assess their mood (range: very unhappy to very happy) and pain scores (range: 0: no pain to 9: worst pain) before and after the session. Parent/ carer questionnaires are collected to assess quality and appropriateness of sessions. Wilcoxon signed-rank tests were performed to compare scores.

Results CHUMS has provided weekly, 2 hour, evening play sessions during the academic year since 2013. A total of 111 parent/carer, 80 0-12 year old and 33 12-16 year old questionnaires were collected. Primary Aim

CHUMS is very popular with the children, especially the long term patients. $92 \%$ of parents/carers strongly agree their child enjoys time with the volunteers; $96 \%$ wish volunteers could spend more time with their child. Secondary Aim significant improvement is seen in pain and mood scores in both age groups; most notable are pain scores in 0-12 year olds with mean score improving from 2.39 before to 1.56 after the session $(\mathrm{p}=0.002)$

Conclusion CHUMS has received tremendous feedback from all involved and has won the PiccaLilly award from the NHS 'Academy of Fabulousness'. It has demonstrated effectiveness in its primary and secondary aims. Its success has inspired a similar initiative, known as Hospital Buddies, on the stroke ward at Manchester Royal Infirmary.

\section{G104(P) SIMULATION IN COMMUNITY PAEDIATRIC TRAINING - A NEW DIMENSION}

M Ramphul, H Alabede, S Ozer. Community Paediatrics, East Hertfordshire NHS Trust, Stevenage, UK

\subsection{6/archdischild-2018-rcpch.101}

Introduction Simulation in medical education aims to recreate a real-life scenario to teach clinicians about dealing with clinical situations before they encounter them in their actual practice. Although simulation has been extensively used in acute paediatrics, its use in community paediatrics is still suboptimal. We believe that community paediatric simulation will create a better rapport between doctors and families, minimise complaints and increase the confidence of doctors dealing with difficult cases. Our aim was to assess the viewpoint of paediatric trainees on the application of simulation teaching in community paediatrics.

Methods We performed a cross-sectional study to look at the perception of level 2(ST4-ST5) and level 3 (ST6-ST8) on the use of simulation teaching in community paediatrics. We collected the responses from trainees using the online survey tool on SurveyMonkey. The figures were analysed on Microsoft Excel, and the qualitative data was collated on Microsoft Word.

Results 27 paediatric trainees responded to our survey, of whom $24(89 \%)$ had used simulation previously. None had used simulation as part of community teaching. The others stated that they had come across simulation as part of their neonatal and acute paediatric training. $83 \%$ of trainees stated that the concept of simulation in community paediatrics had never been introduced to them.

18 trainees (67\%) expressed their wish to have simulation teaching as part of their community training and stated that it would be beneficial in a number of areas such as breaking 
bad news, safeguarding cases, discussions about developmental delay to parents and adoption cases.

We noted that only $23 \%$ of trainees have received some form of training as simulation instructors.

From our survey, we also noted reluctance from some trainees regarding the use of simulation in community teaching.

Conclusion From our study, we have noted that the majority of trainees wish to integrate simulation as part of their community training. Making this a valuable learning exercise for them will require putting in place a robust simulation instruction programme. We are currently in discussion with simulation educators at the University of Hertfordshire to move this programme forwards.

\section{G105(P) SCREENING FOR MENTAL HEALTH CONDITIONS IN CHILDREN WITH EPILEPSY}

${ }^{1} \mathrm{~B}$ Wilkes, ${ }^{2} \mathrm{~S}$ Walsh, ${ }^{1} \mathrm{~A}$ Chryssanthakis, ${ }^{3} \mathrm{O}$ Tame, ${ }^{1} \mathrm{M}$ McGowan, ${ }^{2} \mathrm{G}$ Colville, II Hadjikoumi. 'Paediatric Epilepsy Service, St George's University Hospital, London, UK; ${ }^{2}$ Paediatric Clinical Psychology, St George's University Hospital, London, UK; ${ }^{3}$ St George's Medical School, St George's University of London, London, UK

\subsection{6/archdischild-2018-repch.102}

Background and aims There is a high burden of mental health $(\mathrm{MH})$ problems among children with epilepsy. The relationship between $\mathrm{MH}$ problems and epilepsy is bidirectional with shared risk factors. Our key aims were:

- To determine the prevalence of MH difficulties among the patients of our Secondary Paediatric Epilepsy Service.

- To ascertain if more input from MH services is required within the Secondary Paediatric Epilepsy Service.

- To demonstrate the use of a standardised behavioural screening questionnaire in assessing $\mathrm{MH}$ difficulties.

Methods The Strengths and Difficulites Questionnaire (SDQ) was used to screen for those at risk of, or currently experiencing $\mathrm{MH}$ problems. We received 86 replies and, following exclusions, 64 patients data was analysed. The patient's electronic notes were used to determine diagnoses and medications.

Results $56 \%$ of patients scored high or very high risk for having or developing $\mathrm{MH}$ difficulties. A chi- square test indicated a significant difference $(p<0.001)$ in the proportion of children with epilepsy with clinically significant scores versus the proportion in the community samples. Peer and pro-social subdomains scored in the 'high' risk category whilst the other subdomains scored in 'close to average' risk. Patients not on anti-epileptic drugs have close to average scores. There is trend towards those on more than 1 Antiepileptic drug having higher scores. Developmental disorder increases that risk of having a high or very high score from $43 \%$ to $68 \%$.

Conclusions Our results reflect similar prevalence to that demonstrated in the literature; children with epilepsy have a high risk of developing $\mathrm{MH}$ disorders. Our data highlights the need to improve identification, diagnosis, prevention and management of $\mathrm{MH}$ problems in children with epilepsy on both a national and local level.

\section{G106(P) TARGETED TECHNICAL SKILLS SIMULATION TRAINING HELPS PAEDIATRIC TRAINEES WITH COLLEGE CORE PROCEDURES}

${ }^{1} \mathrm{P}$ Mallett, ${ }^{1} \mathrm{C}$ Watterson, ${ }^{1} \mathrm{C}$ Junk, ${ }^{1} \mathrm{~T}$ Bourke, ${ }^{1} \mathrm{~A}$ Thompson, ${ }^{2} \mathrm{~S}$ Christie. ${ }^{1}$ Paediatric Simulation Education Department, Royal Belfast Hospital for Sick Children, Belfast, UK ${ }^{2}$ School of Paediatrics and Child Health, Northern Ireland Medical and Dental Training Agency, Belfast, UK

\subsection{6/archdischild-2018-rcpch.103}

Aims Acute Paediatrics is a stimulating and challenging training programme. The Royal College of Paediatrics and Child Health (RCPCH) provide a comprehensive curriculum for trainees during these years. In Level 1 Training (ST1-3), there are a number of core practical procedures trainees are expected to perform prior to progression to Level 2 training. These skills include Neonatal Intubation, Lumbar Puncture (LP) and Intraosseous (IO) Access. ${ }^{1}$

Often it may be difficult for trainees to gain significant experience in these skills and achieving competence can be challenging. Reasons for this include lack of opportunity, lack of experience, and low procedural confidence. The RCPCH advocates the delivery of Simulation and Technology Enhanced Learning (TEL) including in the area of technical skills training. ${ }^{2}$

By creating a technical skills simulation training day, we aimed to increase trainee exposure and confidence to core college procedures.

Methods We created a simulation training day for Level 1 Regional Training focused on 3 core procedures. We asked Paediatric ST1-3 trainees about previous teaching, experiences and confidence levels with these skills.

Results 24 ST1-3 trainees were surveyed. Prior to the teaching, $2(8 \%)$ trainees felt their Intubation skills were adequate, $12(50 \%)$ described their LP skills as satisfactory and $4(16 \%)$ trainees labelled their IO access skills as acceptable.

Following the training session, 23 of the 24 trainees (96\%) felt significantly more confident in approaching all 3 of the core practical skills. All 24 Trainees (100\%) felt that simulated practice helped improve their technical skills and all (100\%) felt it would be useful in their daily job.

Conclusion Simulation-based training for procedural skills has been shown to be effective for trainees and has been widely used in many training programs. ${ }^{3}$ By integrating this into the Deanery's Regional teaching programme, we have presented junior trainees the opportunity to gain vital hands-on experience on high-fidelity models, which has improved procedural exposure, enhanced user-confidence and may potentially develop procedural competence. We hope to extend this programme to higher level trainees and incorporate other core procedural skills in a bid to further promote a safe, traineefriendly, patient-centred simulated learning environment.

\section{REFERENCES}

1. Curriculum for Paediatric Training. General paediatrics: Level 1, 2 and 3 training August 2016. http://www.rcpch.ac.uk/training-examinations-professional-development/postgraduate-training/general-paediatrics-training/ge\#curriculum

2. Strategy- Simulation and TEL. Royal college of paediatrics and child health January 2015. http://www.rcpch.ac.uk/training-examinations-professional-development/ postgraduate-training/simulation-and-technology-enh

3. Barsuk JH, Cohen ER, et al. Simulation-based education with mastery learning improves residents' lumbar puncture skills. Neurology 2012;79(2):132-7. 